\title{
REFLEXÕES SOBRE ALGUNS CONCEITOS DA PESQUISA QUALITATIVA ${ }^{1}$
}

\author{
REFLETIONS ABOUT SOME CONCEPTS OF QUALITATIVE RESEARCH
}

\author{
Fredy Enrique González ${ }^{2}$
}

\begin{abstract}
Resumo: Neste ensaio são apresentadas algumas reflexões relacionadas com conceitos frequentemente usados nas pesquisas chamadas qualitativas. A primeira questão que é colocada é o conceito mesmo do que é Pesquisa Qualitativa (PQ), fazendo ênfase que essa expressão faz alusão de uma variedade grande de formas de pesquisar assuntos sociais e educacionais. Após são oferecidos dez critérios para identificar variantes e invariantes entre as diversas famílias de PQ. A seguir é descrito o papel do pesquisador na Pesquisa Qualitativa, dando destaque ao Lugar Epistemológico ocupado pelo pesquisador neste tipo de pesquisa e aos compromissos cognitivos que são assumidos pelo pesquisador qualitativo. Logo, são abordados o conceito de triangulação e a Entrevista como técnica privilegiada para obter informações em Pesquisa Qualitativa. O trabalho conclui deixando em aberto a reflexão sobre os assuntos desenvolvidos no ensaio.
\end{abstract}

Palavras-chave: Variantes e Invariantes; Triangulação; Enquque Pentadimensional; Lugar Epistemológico.

\begin{abstract}
In this essay some reflections related to concepts frequently used in qualitative research are presented. The first question that is asked is the concept of what is Qualitative Research (PQ), highlighting that this expression alludes to a wide variety of ways of researching social and educational issues. Afterwards, ten criteria are offered to identify variants and invariants among the different PQ families. The researcher's role in Qualitative Research is described below, highlighting the Epistemological Place occupied by the researcher in this type of research and the cognitive commitments that are assumed by the qualitative researcher. Therefore, the concept of triangulation and the Interview as a privileged technique for obtaining information in Qualitative Research are addressed. The work concludes by leaving open the reflection on the subjects developed in the essay.
\end{abstract}

Keywords: Variants and Invariants; Triangulation; Pentadimensional approach; Epistemological Place.

\section{Introdução}

Em torno da pesquisa qualitativa e suas diferenças com a pesquisa quantitativa, há muitas questões que ainda precisam ser esclarecidas; há quem acredita que as controvérsias entre as perspectivas quantitativa e qualitativa na pesquisa socioeducativa constituem "uma controvérsia em extinção" (RODRÍGUEZ REVOREDO, 2015); outros afirmam que "o debate deve continuar" e que "a discussão ainda é necessária" (GONZÁLEZ, 2006) dado que a pesquisa qualitativa ainda tem que enfrentar inúmeros

\footnotetext{
${ }^{1}$ Esse artigo é uma versão atualizada do trabalho originalmente publicado por: GONZÁLEZ, F. E. Apuntes Acerca de Algunos Conceptos Básicos de Investigación Cualitativa Sapiens. Revista Universitaria de Investigación, año 4, n. 1, p. 107-132, 2003.

2 Doutor en Educación (Énfase em Educação Matemática) pela Universidad de Carabobo - UC (Venezuela); Professor da Universidade Pedagógica Experimental Libertador (UPEL); Professor Visitante da UFRN - Centro de Educação -Departamento de Práticas Educacionais e Curriculo - Programa de PósGraduação em Educação - PPGEd. ORCID: http://orcid.org/0000-0002-8079-3826 E-mail: fredygonzalezdem@gmail.com
} 
desafios (BOSI, 2014). Alguns desses desafios são: (a) defender a sua legitimidade como opção para a produção de conhecimentos sobre assuntos sociais e humanos (estatuto epistemológico); (b) Superar a tensão semântica, multidimensionalidade intrínseca e multidimensionalidade extrínseca inerentes ao conceito de pesquisa qualitativa" (BOSI, 2012, p. 577); (c) Superar a dispersão semântica frequentemente associada com a expressão "pesquisa qualitativa" manifesta na multiplicidade de taxonomias, nomenclaturas e vertentes que não permitem apreciar as invariantes e variantes próprias das diferentes opções de pesquisa qualitativa; (d) desenvolver programas adequados de formação de pesquisadores qualitativos; (e) formular estratégias que garantem a apropriação e o reconhecimento social dos saberes gerados pelas pesquisas qualitativas, dentre outros.

\section{0 que é Pesquisa Qualitativa?}

Essa questão pelo o que da Pesquisa Qualitativa é de natureza ontológica. Referese ao ser desse modo de abordar a constituição de conhecimentos sobre assuntos sociais e educacionais. Para oferecer uma resposta possível (e não a resposta), deve-se levar em consideração que com a expressão Pesquisa Qualitativa se faz referência a uma ampla gama de perspectivas, modalidades, abordagens, metodologias, desenhos e técnicas utilizadas no planejamento, condução e avaliação de estudos, indagações ou investigações interessadas em descrever, interpretar, compreender, entender ou superar situações sociais ou educacionais consideradas problemáticas pelos atores sociais que são seus protagonistas ou que, por alguma razão, eles têm interesse em abordar tais situações num sentido investigativo (JACOB, 1987; JORDAN, 2018).

Isso significa que a expressão Pesquisa Qualitativa quando usada de forma geral, não faz referência a uma entidade unitária; pelo contrário, nesse caso tem um caráter polissêmico porque refere práticas várias de indagação do social. Portanto, o escopo da pesquisa qualitativa é amplo e variado; essas características são uma das razões pelas quais na literatura especializada (BICUDO; COSTA (2019); BOGDAN; BIKLEN (1982); DENZIN; LINCOLN (1994); EISNER (1991); LINCOLN; GUBA (1985); MARTÍNEZ (1989, 1991, 2000), PATTON (1990)) aparecem termos, palavras e expressões que, quando se referem a uma gama de noções diferentes, propiciam uma exuberância discursiva e polissêmica (TAQUETTE; MINAYO, 2016) que gera uma 
grande "tensão semântica" (BOSI, 2012); por isso é necessário fazer um esclarecimento tanto conceitual quanto terminológico de seu significado.

A primeira coisa que temos a dizer é que existem várias maneiras de realizar pesquisas sociais e educacionais caracterizadas como qualitativas: como, por exemplo, Histórias de Vida (CÓRDOVA, 1995; PUJADA, 2002); Etnografia (GOETZ; LECOMPTE 1988; MARTÍNEZ, 1991, 2000); Pesquisa-Ação (ENRIQUEZ; VILLAZÓN, 1995; KEMMIS; MCTAGGART, 1992); entre outros (BICUDO, KLÙBER, 2013; JACOB, 1987; MARTÍNEZ, 1989; MARTINS; BICUDO, 1994), que compartilham um conjunto de características definidoras. Porém, cada uma delas possui algumas características próprias que servem para diferenciá-las das outras; para o autor deste ensaio, as características comuns são chamadas Invariantes, enquanto às Variantes são as características que permitem apreciar as diferenças entre as várias maneiras qualitativas de desenvolver pesquisa socioeducativa. Esse assunto é tratado na sessão a seguir.

\section{Invariantes e Variantes ${ }^{3}$ na Pesquisa Qualitativa}

Uma das frases que, recorrentemente, é encontrada em artigos ou relatórios de pesquisa qualitativa é a expressão "a metodologia qualitativa"; o autor considera esta frase errada porque o uso do artigo singular " $a$ " não permite apreciar a grande variedade das abordagens enquadradas na perspectiva qualitativa da pesquisa.

Portanto, é conveniente propor alguns critérios com base nos quais a multiplicidade de possíveis modalidades de pesquisa qualitativa possa ser abordada com propriedade; é necessário saber quais são suas invariantes, ou seja, aqueles aspectos que são compartilhados por todas ou pelo menos a maioria das maneiras de realizar pesquisas qualitativas e, também é importante saber em que níveis suas variantes são apresentadas, ou seja, suas diferenças sutis mas significativas. Para realizar esta tarefa, o autor propõe os critérios que são indicados a seguir:

\section{Fontes Disciplinares}

- Refere-se aos campos disciplinares que fornecem as principais contribuições teóricas, conceituais e cognitivas que compõem o discurso da modalidade considerada (por exemplo, Antropologia, Sociologia, Psicologia, etc.)

\section{Autores ou Promotores Fundamentais}

\footnotetext{
${ }^{3}$ Trate-se de um uso livre desta expressão de aplicação frequente na linguística (MOREIRA, 2018).
} 
- Refere-se a pensadores cujas ideias mais contribuíram para a caracterização da modalidade investigativa (por exemplo, Maria Aparecida Viggiani Bicudo, Franco Ferraroti, Barney Glasser, Anselm Strauss, Edmund Husserl, Egon Guba, Alejadro Moreno, dentre outros)

\section{Procedimentos Privilegiados}

- Constituem os recursos, instrumentos, técnicas e métodos que normalmente compõem a estratégia a ser desenvolvida para obter informações quando são realizados estudos enquadrados em uma determinada modalidade de pesquisa qualitativa (por exemplo, gravadores de áudio e de vídeo, questionários, entrevistas, observação participante, etc.)

\section{Assunto da atenção investigativa}

- Refere-se à dimensão ontológica da modalidade e indica o aspecto da realidade em que o pesquisador tem interesse (por exemplo, ações, expressões e sentimentos das pessoas; expressão, na vida individual de uma pessoa, de uma história social coletiva; significado atribuído às suas ações pelos protagonistas de uma situação social específica; significado subjetivo da ação social; estilo de vida de um grupo de pessoas; vida cotidiana em uma comunidade; experiências socio-simbólicas de uma estrutura social etc.)

\section{Papel desempenhado pelo pesquisador.}

- Indica o grau de compromisso assumido por quem é responsável pela realização da investigação (por exemplo, ativo, envolvido, comprometido, imerso na realidade em estudo)

\section{Pontos de deslocamento no foco da atenção.}

- Constituem as várias fases ou etapas pelas quais o objeto de investigação privilegiado passou pela modalidade (v. g.: de "relações que se referem à cultura de comunidades exóticas no exterior" e "descrição densa do que acontece diariamente na sala de aula")

\section{Evolução Histórica}

- Constitui o processo de ajuste progressivo de questões cruciais dentro da modalidade (por exemplo, estudos pioneiros, modificações no objeto de estudo, incorporação de ferramentas analíticas, esclarecimentos conceituais, etc.)

\section{Significado Etimológico}


- Refere-se à etimologia da palavra usada para denotar a modalidade (por exemplo, Etnografia: ethno (povo), graphé (descrição); descrição de um povo)

\section{Características Específicas}

- Constituem aspectos característicos da modalidade (por exemplo, suspender as pre-cognições e preconceitos é uma característica específica da Fenomenologia epoché)

\section{Pressupostos fundamentais}

- São os fundamentos filosóficos, epistemológicos e disciplinares assumidos como princípios ou postulados pela modalidade (v.g. É possível estudar uma realidade social através de um exame minucioso da história de vida de um sujeito significativo ou informante chave).

As invariantes podem ser identificadas levando em consideração as dimensões:

1. Metodológica: técnicas, métodos e procedimentos utilizados na estratégia para obteção e tratamento da informação pertinente para construir os dados da pesquisa (3. Procedimentos Privilegiados).

2. Ontológica: aspecto da realidade que interessa ao pesquisador (4. Assunto da atenção investigativa).

3. Axiológica: valores e princípios éticos que são assumidos.

4. Teleológica: objetivos e metas da pesquisa. As várias modalidades de pesquisa qualitativa não procuram explicações (relações causa-efeito) para os assuntos pesquisados senão compreendê-los, levando em consideração o contexto natural onde tais assuntos acontecem.

Além do anterior, as pesquisas ditas qualitativas, compartilham (têm como invariantes) as características seguintes: (a) estão interessadas na essência dos processos sociais; (b) concebem as situações sociais como um sistema com alto nível de complexidade; (c) os pesquisadores adotam uma visão sistêmica da realidade; (d) não estabelecem um modelo rígido, nem prescrevem um esquema estruturado tipo receita de cozinha, mas o processo de pesquisa é desenvolvido com grande flexibilidade; (e) dão destaque à parte subjetiva da vida; (f) são orientados para "a compreensão das ações sociais, considerando a ação particular de cada ator social, sob sua própria perspectiva e a do pesquisador" (TORRES, 1999, p. 4); (g) são trabalhos de natureza "sócio ecológica" (OSTROM, 2009). 
Mas a invariante fundamental de todas as pesquisas qualitativas é a reivindicação da legitimidade que tem a subjetividade, tanto do pesquisador quanto das outras pessoas que participam como interlocutores na pesquisa, como fonte para a produção de conhecimentos e saberes.

Em quanto às variantes, podem ser localizadas fazendo uma imersão nas fontes filosóficas, disciplinares e históricas da modalidade que está sendo analisada; por exemplo, no caso da etnografia, pelo menos três correntes podem ser identificadas: (a) americana (JACOB, 1987), que assume uma abordagem cultural, com ênfase na descrição de culturas em risco de extinção que, portanto, elas devem ser preservadas; (b) britânica (ATKINSON, DELAMONT; HAMMERSLEY, 1988), cuja abordagem é socializadora e enfatiza a consciência da necessidade de destacar ou chamar a atenção para a presença de certas culturas cuja existência deve ser reconhecida; e (c) Latino Americana (FALS-BORDA, 2009; MONTERO-SIEBURTH, 1993ç MORENO, et al., 2009), com ênfase predominantemente política que busca transformar para melhorar as condições de vida dos membros de comunidades economicamente desfavorecidas. Para saber mais, consulte: Myers (2020).

\section{O Papel do pesquisador na Pesquisa Qualitativa}

O pesquisador, na pesquisa qualitativa, é assumido como um sujeito que pensa, percebe, sente, expressa interesse pelo assunto que deseja pesquisar. Um sujeito cognoscente. Assim, o pesquisador, em tanto que sujeito senti-pensante não pode se afastar do acontecemento que está pesquisando e que se dá a sua percepção.

Entre Sujeito/Pesquisador e Acontecemento/Pesquisado não existe uma dualidade. Ao contrário, Sujeto (Pesquisador)/Acontecemento(Pesquisado) dá-se como uma unidade indivisível, baseada na subjetividade própria do pesquisador, quem é considerado como o principal meio para ter acesso à informação relevante para construir a resposta à pergunta (questão) de pesquisa. Assim pesquisador é considerado o Dispositivo Principal das Pesquisas Qualitativas.

Na pesquisa qualitativa, mais que em qualquer outra modalidade de produção de conhecimento, o pesquisador tem um lugar privilegiado desde o qual ele pode exercitar a sua subjetividade a plenitude. $\mathrm{O}$ acontecimento pesquisado, remete para ações postas em jogo por seres humanos que sintetizam em si as dimensões sociosimbólica, referida à forma como o pesquisador se reconhece a si mesmo e se apresenta diante dos outros, 
como resultado da metabolização (HIDALGO; GONZÁLEZ, 2009) ou absorção das múltiplas condições (geográficas, históricas, sociais, culturais, familiares, tecnológicas, econômicas, políticas, religiosas, entre muitas outras) nas quais desenvolve sua vida (CÓRDOVA, 1995), e contribuem ao desenvolvimento da sua subjetividade, que condiciona todos os processos cognitivos, afetivos e sensoriais que mediam seu relacionamento com a realidade constituída pelas condições antes ditas.

Tais condições pela sua vez são o alicerce sobre o qual o pesquisador constrói e desenvolve suas ações em tanto que sujeito. Isso acontece porque vivemos como indivíduos singulares mas, ao mesmo tempo somos vividos em tanto que sujeito sociais. E é essa relação dialéctica entre nosso $e u$ (singular) e nosso nós (social) que faz que sejamos aquilo que somos. O primeiro tem caráter sociosimbólico e o segundo tem caráter sócioestrutural.

A socioestrutura está constituida pelos contextos onde desenvolvemos nosso efêmero tempo vital, onde vivemos cotidianamente nossa vida. Assim, cada um de nós possui duas biografias: uma Biografia Individual (autobiografia) que é singular (aquela pela qual construímos individualmente uma versão de nós mesmos) e uma "Biografia Coletiva" (MONTAGNER, 2009) que dá destaque às relações sociais e interpessoais que cada um de nós estabelece como os outros.

Mas, mesmo que implícitas, toda Biografia Individual contém "invariantes estruturais", o seja "convergências que emergem tematicamente nas histórias de vida singulares (autobiografia) no interior de um horizonte histórico dado (biografia coletiva)" (FERRAROTTI, 2014, p. 51, grifo nosso).

É o mesmo Ferraroti (2014) que acrescenta o anterior afirmando que

Qualquer prática individual humana é uma atividade sintética, uma totalização
ativa de todo o contexto social. Uma vida é uma prática que se apropria das
relações sociais (as estruturas sociais), as interioriza é as reconverte em
estruturas psicológicas através de sua atividade de desestruturação-
reestruturação. Cada vida humana revela-se, mesmo em seus aspectos mais
generalizáveis, como a síntese vertical de uma história social. Cada
comportamento cada ato individual aparece, em suas formas mais singulares,
como a síntese horizontal de uma estrutura social (FERRAROTTI, 2014, p. 70,
sublinhado nosso).

Essa singularidade individual -que tem "qualquer prática individual humana", como Ferraroti diz- permite assumir ao pesquisador como o principal Dispositivo da Pesquisa Qualitativa.

O vocábulo dispositivo é polissêmico. Os pesquisadores Pezzato; Botazzo; L'Abbate (2019, p. 299), fizeram uma pesquisa aleatória nos indexadores da literatura 
cientifica contemporânea e confirmaram a polissemia e dispersão de significados atribuídos à palavra dispositivo.

Mas, quando referido ao pesquisador como dispositivo, estamos assumindo-o como alguém que tem disposição, que está disposto para gerar conhecimentos, desenvolvendo pesquisa, sobre algum assunto de seu interesse. A pesquisa é uma prática individual (mas não em solidão) que o move e o comove como ser humano. Movimentando num tecido complexo suas cognições, suas emoções, suas crenças. Assim, o pesquisador qualitativo não pode se afastar de seu assunto de pesquisa porque está imerso, embebido, embutido, implicado, nele com sua carga de subjetividade toda.

De ali que a pesquisa qualitativa seja tão desafiadora na medida que os pesquisadores qualitativistas têm que lidar com uma dinâmica dupla de imersão e contemplação hermenêutica, para capturar, coletar e registrar informações que sirvam de base para a emissão de julgamentos, tomada de decisões, apresentação de argumentos, formulação de críticas, identificação de discrepâncias, proposição de soluções para problemas, etc., questões que precisam estar em sintonia com os propósitos, objetivos ou metas delineados no respectivo projeto de pesquisa; o seja, com a sua dimensão teleológica.

Quem, melhor que um ser humano, pode realizar um processo investigativo que exige tanta sensibilidade (definida como a capacidade de captar a presença de um determinado elemento em seu ínfimo nível de existência), tal como são as pesquisas qualitativas que (a) têm como assunto de interesse os aspectos subjetivos das ações humanas e sociais; (b) propõe-se compreender e descrever em profundidade, através de conceitos teóricos, a dinâmica social de grupos, movimentos e sociedades, bem como compreender (capturar) os acontecimentos com base nos significados que eles têm para aqueles que são seus protagonistas; interpretar os fatos que ele vive e observa; criar uma imagem fiel e realista do assunto estudado e contribuir para a compreensão de grupos com características semelhantes; (c) procura uma "descrição densa" (GEERTZ, 2008) do contexto e do significado dos fatos da vida social, usando múltiplas técnicas, como a realização de observação participativa (PERUZZO, 2017) e entrevistas em profundidade (MARTINO; LOPES; SOUZA, 2019; MORÉ, 2015; SANTOS et al., 2016) com informantes-chave ou sujeitos significativos (BISOL, 2012; RENOSTO; TRINDADE, 2007); (d) confia em uma troca múltipla de pontos de vista: o dele com os dos outros atores sociais com quem ele interage nas múltiplas situações sociais onde sua vida esteja acontecendo; e (e) enfatiza as inter-relações holísticas (internas) e ecológicas (entre) que 
interligam os acontecimentos as pessoas que participam deles e o contexto em que eles têm lugar; lembrando que entre aquilo que é holístico e o que é ecológico, como Capra e Steindl-Rast (1998) dizem, existem diferenças importantes:

\begin{abstract}
$\mathrm{Na}$ verdade, enfatizei recentemente que é importante conhecer a diferença entre holístico e ecológico. Uma visão de mundo ecológica é holística, mas é mais do que isso. Não só olha para alguma coisa como uma totalidade, mas também para o modo como essa totalidade está embutida dentro de totalidades maiores. Isso é especialmente importante quando se estudam sistemas vivosorganismos vivos, ecossistemas, e assim por diante- mas também pode ser aplicado a coisas não vivas (CAPRA; STEINDL-RAST, 1998, p. 71, grifo nosso).
\end{abstract}

A magnitude do compromisso que um pesquisador qualitativo assume com seu assunto de estudo é uma condição essencial para oferecer garantias quanto à robustez das informações que ele coleta; isso requer não apenas habilidade e prontidão, mas, fundamentalmente, sensibilidade (veja a definição acima); isso se manifesta através: do grau de consciência do pesquisador para captar as sutilezas de significado implícitas na informação; da sua capacidade para perceber as conexões não explícitas entre as várias unidades constitutivas dessa informação; da sua capacidade de conferir sentidos e significados a eventos ou situações que parecem não ter transcendência nenhuma; da sua capacidade de compreender e de distinguir o que é pertinente do que não é; portanto, ao pesquisador qualitativo é exigido: consciência, discernimento, imaginação, visão transdutiva (do particular para o particular; fundamental na "análise comparativa constante dos dados", segundo SANTOS; CUNHA; ADAMY; BACKES; LEITE; SOUSA, 2018; STRAUSS; CORBIN, 2008) e não só indutiva (do particular para o geral) ou dedutiva (do geral para o particular), e agudeza; não existe instrumento nenhum de "lápis e papel" ou algum "dispositivo tecnológico" que possa exibir um grau de sensibilidade superior ao de uma pessoa devida e suficientemente treinada para atender às necessidades de uma perspectiva predominantemente qualitativa de pesquisa.

No caso de um pesquisador qualitativo de qualidade, esta-se em presença de alguém que: está ciente de seu ambiente; é capaz de interagir com os protagonistas de situações sociais que contextualizam o assunto de seu interesse, sem interferir nas ações que constituem as referidas situações; tem a capacidade de desempenhar simultaneamente vários papéis em diferentes níveis (por exemplo, pesquisa em sala de aula, realizada pelo próprio professor, atuando como facilitador e pesquisador. Ver: González, 1997; Villegas; González, 2005); pode assumir uma perspectiva holística e ecológica em seu cenário de estudo; tem a capacidade de processar informações com rapidez incomum; é capaz de dar feedback e solicitar esclarecimentos em tempo real; tem a possibilidade de 
examinar respostas atípicas ou inesperadas e de se relacionar diretamente com o contexto da investigação; tem capacidade para pensar, fazer julgamentos e desenvolver opiniões com sentido e significado; e, finalmente, pode construir argumentos válidos, formular críticas informadas e apontar discrepâncias fundamentadas. (Para saber mais: BICUDO; COSTA, 2019; EISNER, 1991; GLASER; STRAUSS, 1967; LINCOLN; GUBA, 1985; MELLA, 1998; PATTON, 1990; RUSQUE, 2001; STRAUSS; CORBIN， 1990; VILLEGAS, 2003).

No entanto, dada a magnitude da responsabilidade que o pesquisador possui em um processo de investigação qualitativa, ele tem uma obrigação moral e ética de declarar explicitamente quais são as coordenadas teórico-conceituais que fornecem coerência, direção e transcendência ao seu trabalho de pesquisa; tais coordenadas são as que definem seu Lugar Epistemológico; a próxima parte deste artigo é dedicada a esse conceito.

\section{O Lugar Epistemológico do pesquisador na Pesquisa Qualitativa}

O Lugar Epistemológico é a posição a partir da qual o pesquisador produz conhecimentos e saberes; esse posicionamento está associado à história de sua vida, à sua formação pessoal e profissional, bem como às marcas deixadas nele pelas suas vivências e outras experiências vitais que ele teve como ser humano. No caso de pesquisadores qualitativos, observa-se frequentemente que eles têm uma visão sistêmica da realidade; por esse motivo, concebem as situações que estudam como sistemas complexos situados sócio - geograficamente; isso significa que eles estão preocupados com

$$
\begin{aligned}
& \text { o estudo de situações sociais, tal como elas acontecem no âmbito de seu próprio } \\
& \text { contexto ecológico e sociocultural, levando em consideração as condições } \\
& \text { normais das ações humanas e sociais e a complexidade que caracteriza essas } \\
& \text { situações para descrevê-las e alcançar uma interpretação e compreensão } \\
& \text { adequadas delas (HERNÁNDEZ, 1999, outubro, p. 3). }
\end{aligned}
$$

Os pesquisadores qualitativos também escolhem, como assuntos de pesquisa, os eventos aos quais eles atribuem uma valorização importante, o que possibilita ao pesquisador estabelecer uma relação íntima com sua área de investigação (ALVARADO, 2003, maio).

As dimensões do Lugar Epistemológico de um pesquisador são duas. A primeira tem caráter situacional, baseia-se no seguinte princípio básico: tradições, papéis, valores e normas, entre outras características, da sociedade (escopo, contexto) em que as pessoas desenvolvem o quotidiano de suas vidas, gradualmente são internalizadas por elas, gerando assim regularidades que, usadas adequadamente, podem dar conta (explicar) ou 
servir de base para a compreensão do significado e do sentido das ações das quais são protagonistas tais pessoas (consideradas individualmente ou agrupadas coletivamente) quando participam de determinadas situações sociais (MARTÍNEZ, 1989).

O exposto acima contribui para constituir uma perspectiva para cada pessoa, a partir da qual, como ator social, dá sentido ou significado às ações nas que ele participa, às outras pessoas que intervêm com ele nas situações sociais das quais são protagonistas ou espectadores (diretos ou indiretos), às circunstâncias, aos eventos e, em geral, a tudo o que acontece em seu espaço habitual de atuação. Assim, as pessoas constroem e reconstroem o significado que atribuem às suas ações com base nas experiências que tiveram em contextos particulares. Essas experiências constituem a dimensão situacional da definição de Lugar Epistemológico.

A segunda das dimensões definidoras do Lugar Epistemológico tem nuances marcadamente idiossincráticas, uma vez que se relaciona com às qualidades do pesquisador associadas com sua habilidade e experiência no processamento de informações. Nesse sentido, são essenciais a sua sensibilidade e a sua perspicácia (condição que possibilita a apreciação de detalhes sutis, quase imperceptíveis, presentes nas situações em estudo) e o seu nível de consciência metacognitiva, ou seja, a capacidade de estar ciente da sua própria dinâmica cognitiva e das suas emoções, sentimentos, e afetos em geral (GONZÁLEZ, 1993/96; GONZÁLEZ, 2009).

Essas duas dimensões, situacional (contexto da vida) e idiossincrática (metabolização pessoal das condições situacionais), são integradas, dando origem a uma perspectiva (posição ou abordagem) a partir da qual o pesquisador constrói o conhecimento e gera saberes, condicionado tanto pela formação, pela experiência e pelo conhecimento anterior, quanto pela natureza da relação estabelecida com as situações sociais que captam sua atenção investigativa e por causa de sua carga afetiva, de valores, pressupostos cognitivos e tudo o que é próprio dele, tanto por sua condição de ser humano quanto por sua condição de ser social. Na Figura 1 são mostradas as dimensões do Lugar Epistemológico. 
Figura 1: Componentes do Lugar Epistemológico

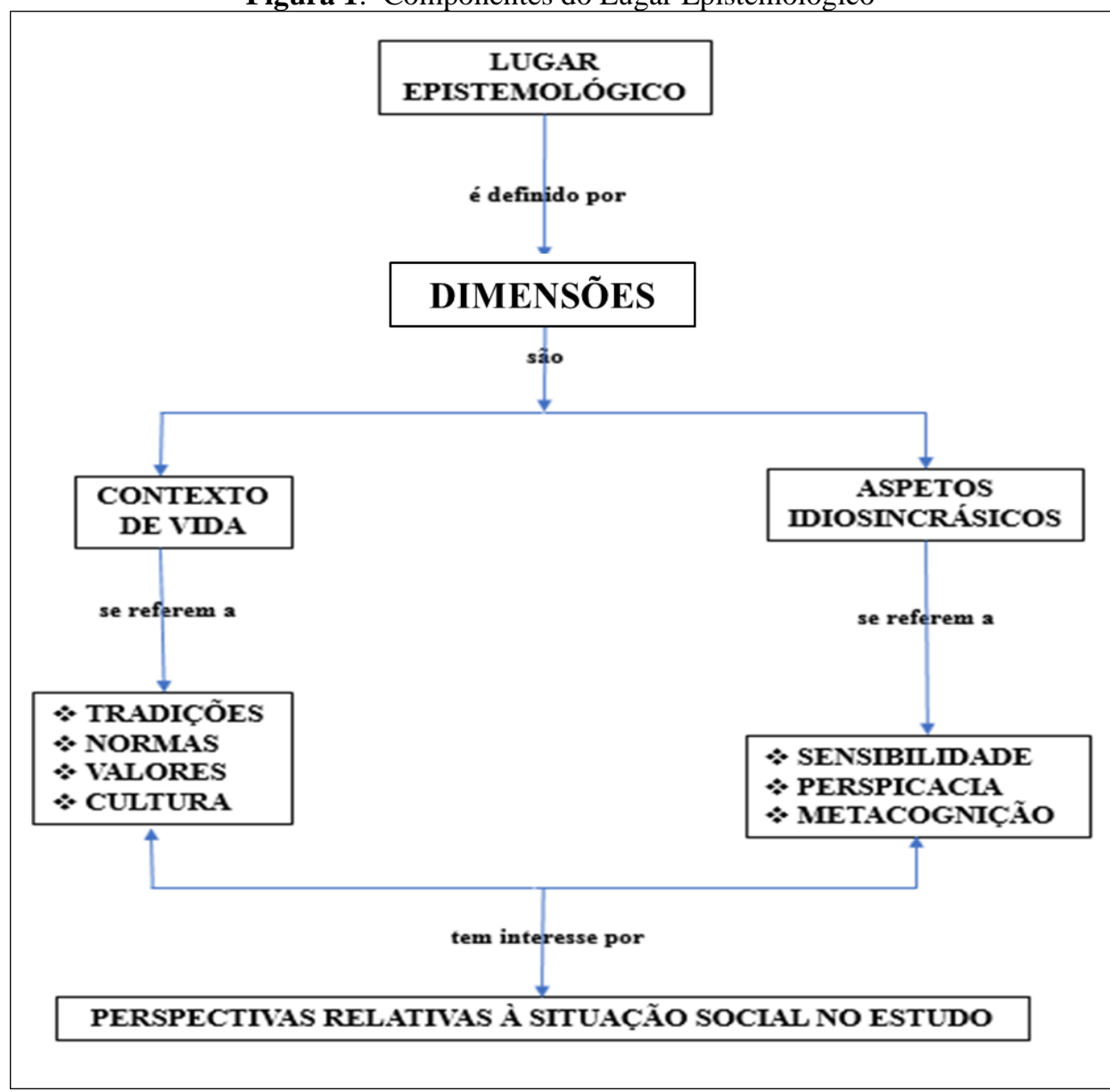

Fonte: Autoria Própria

Em resumo, ao explicitar seu Lugar Epistemológico, o pesquisador admite que atua dentro de uma trama complexa de interações sociais (CAPRA, 1998), constituindo a dimensão situacional (situações sociais nas quais ele já atuou anteriormente; tradições nas instituições onde foi educado e/ou escolaridade; traços característicos de seu gentilício nativo; costumes predominantes em seu campo de atuação profissional; práticas dos grupos sociais, esportivos, políticos, acadêmicos e profissionais aos quais ele está ligado); e, exibindo toda competência e capacidade adquirida pela sua condição de processador ativo de informações (como ser humano, o pesquisador qualitativo tem a capacidade de: escutar, ouvir, imaginar, pensar, tocar, sentir, degustar, manusear, etc. Todos esses sistemas permitem extrair informações de seu contexto e processá-las). Esse caráter da segunda dimensão do Lugar Epistemológico possui nuances cognitivas e gera um conjunto de compromissos, que serão detalhados a seguir. 


\section{Compromissos cognitivos do pesquisador qualitativo}

O estilo de pensamento do pesquisador qualitativo (e em geral de todo pesquisador) é uma função do lugar epistemológico (modos de ver o mundo) que ele adota; compromete-o com alguma maneira de abordar / perguntar sobre a realidade, o que implica, explicitamente ou não, uma posição ontológica, isto é, uma concepção sobre o que é a realidade. De tal maneira que, quando ele é interrogado por ou ele interroga ao mundo, o pesquisador compromete-se tanto cognitivamente quanto ontológicamente.

Além disso, ele também está envolvido no axiológico, em virtude de sua abordagem respeitosa com os outros (por exemplo, seus informantes-chave ou sujeitos significativos para sua pesquisa), e também no teleológico, porque seu ato é um ato pleno de intenções, ou seja, é uma ação humana. Portanto, a atividade cognitiva do pesquisador qualitativo adquire significado apenas na medida em que está vinculada com o resto das dimensões da tarefa investigativa; por tanto, o cognitivo, axiológico, epistemológico e teleológico constituem uma integralidade sistêmica nas ações do pesquisador qualitativo.

A seguir são exhibidas algumas das combinações possíveis do funcionamento cognitivo do pesquisador com as dimensões da tarefa investigativa.

\subsection{Cognição e Teleologia}

A dimensão teleológica da pesquisa refere-se ao seu propósito, ou seja, à intencionalide que o pesquisador tem com seu trabalho. Algumas das intenções frequentemente atribuídas à pesquisa qualitativa são as seguintes: (a) entender em detalhes a perspectiva de outras pessoas; (b) reconstruir a dimensão social do indivídual; (c) tornar inteligível o modo de vida dos outros; (d) reconstruir a história; (e) apropriarse dos significados que os informantes-chave ou sujeitos significativos atribuem aos elementos do contexto; (f) interpretar ações humanas e sociais.

Portanto, compreender, reconstruir, apreender e interpretar são alguns dos principais compromissos cognitivo-teleológicos do pesquisador qualitativo, que se opõem à intencionalidade teleológica explicativa do pesquisador quantitativo; o explicar, típico da pesquisa quantitativa, faz uma diferença substantiva, com o compreender, o que é a intenção esencial da pesquisa qualitativa. Esta questão será explorada em mais detalhes a seguir.

Do ponto de vista conceitual, explicar e compreender são duas noções que requerem compromissos cognitivos completamente diferentes que viabilizam o 
desenvolvimento de pesquisas em direções nas quais uma não exige a outra. No Quadro 1 são indicados os compromissos de explicar e compreender a partir das categorias do Enfoque Pentadimensional, um recurso heurístico para organizar a leitura crítica de trabalhos escritos o relatóricos de pesquisa (GONZÁLEZ, 2005, 2008).

Quadro 1: Diferenças entre Explicar e Compreender a partir do Enfoque Pentadimensional

\begin{tabular}{|c|c|c|}
\hline EXPLICAR & $\begin{array}{c}\text { CATEGORIAS DO } \\
\text { ENFOQUE } \\
\text { PENTADIMENSIONAL }\end{array}$ & COMPREENDER \\
\hline Objeto & $\begin{array}{c}\text { ONTOLOGÍA } \\
\text { (faz ênfase })\end{array}$ & Sujeito \\
\hline Relação Causa-efeito & $\begin{array}{c}\text { TELEOLOGÍA } \\
\text { (pretende-procura })\end{array}$ & Sentido/significado da ação \\
\hline Análise & $\begin{array}{c}\text { METODOLOGÍA } \\
\text { (procede por })\end{array}$ & Imersão \\
\hline Por que? & $\begin{array}{c}\text { AXIOLOGÍA } \\
\text { (dá destaque })\end{array}$ & Para que? \\
\hline Cognição & $\begin{array}{c}\text { EPISTEMOLOGÍA } \\
\text { (opera ao nível da })\end{array}$ & Metacognição \\
\hline
\end{tabular}

Fonte: Autoria Própria

Outro critério para diferenciar o Explicar (E) do Compreender (C) é a qualidade do saber produzido através de um processo ou outro; na explicação, o saber é nomotético (generalização, busca do universalmente válido), enquanto no compreender é ideográfico (particularização, o singular, único, irrepetível); no primeiro, busca-se a lei (prever e controlar a operação do objeto); no segundo, busca-se o sentido / significado da ação humana (compreender e respeitar o sentimento do ator) (SALAS SOLIS, 2005).

Outra díade frequente na pesquisa qualitativa que também deve ser elucidada é que Compreender e "Procurar uma Solução", são duas manifestações teleológicas diferentes e nem sempre são reconciliáveis no âmbito de uma mesma investigação. A compreensão é obtida pela rota hermenêutica fenomenológica (BICUDO; COSTA, 2019), enquanto a solução é acessada pela rota da Pesquisa-Ação. Compreender requer interpretar e captar de forma empática o significado que uma ação (desde que seja vivida por seu ator) tem para quem a executa.

\subsection{Cognição e Epistemologia}

Uma ideia básica na pesquisa qualitativa é aquela segundo a qual os dados não são fornecidos, eles não têm existência por si mesmos, senão que são construídos pelo pesquisador, trabalhando cognitivamente com as informações que, como principal dispositivo da sua pesquisa, ele coleta. Portanto, o pesquisador deve estar ciente de todos 
os problemas epistemológicos envolvidos na questão dos dados; isso porque coletar, elaborar, captar, procurar, dentre outros, são compromissos epistemológicos diferentes.

Assim, considerando que o pesquisador pensa, constrói raciocínios, elabora conjecturas, cria hipóteses, a partir de seu Lugar Epistemológico específico, um processo de legitimação da subjetividade como fonte de produção do conhecimento é produzido; isso significa que na pesquisa qualitativa acontece uma reivindicação epistemológica do subjetivo, expressada através das cognições do pesquisador.

\subsection{Cognição e Ontologia}

Quando se diz que o pesquisador qualitativo lida com as atuações, comportamentos e expressões escritas ou orais dos atores, duas dimensões da pesquisa qualitativa estão sendo ligadas: a ontológica e a epistemológica. Por um lado, há o caráter ou aspecto (ou a materialização, ou a corporização) que adquire, o conhecimento ou saber produzido: descrições densas, detalhadas, pormenorizadas, profundas (GEERTZ, 2008) de situações ou realidades sociais que se manifestam como condutas e comportamentos das pessoas como atores sociais (ou seja, protagonistas de situações sociais de interesse para o pesquisador) ou como "objetivações materiais" das referidas ações (expressões orais e/ou escritas dos referidos atores).

Descrever e observar são manifestações epistemológicas (na medida em que constituem ações orientadas à produção de conhecimento e saber) exercidas sobre as diversas manifestações das ações humanas (condutas, comportamentos, expressões orais e/ou escritas) que constituem sua dimensão ontológica.

Em resumo, os compromissos cognitivos do pesquisador em geral, e em particular daqueles que assumem algumas das modalidades qualitativas, derivam de sua condição de ser humano capaz de se relacionar com seus pares e de compartilhar significados por meio de ações comunicativas (HABERMAS, 1984, 1987) que carregam informações. O processamento pelo pesquisador de tais informações serve de base para uma construção do conhecimento baseada em uma atividade coletiva de geração de saber, na qual participam diversos atores sociais, além do próprio pesquisador que, dessa forma, é compelido a descrever e interpretar as realidades sociais em estudo, levando em consideração o ponto de vista de seus correspondentes co-protagonistas.

Para isso, é essencial que o pesquisador assuma uma atitude de intropatía com seus sujeitos significativos (informantes-chave). Na pesquisa qualitativa, especialmente 
naquela que assume a perspectiva fenomenológica, e essencial a noção de intropatía e, segundo Bicudo (2016),

A intropatia é basicamente conhecimento do outro que se desenvolve nas vivências em que o outro é dado (trazido, exposto) ao eu em sua corporeidade. É uma percepção constituinte da intersubjetividade. Não se trata, assim, de um conceito teórico ou de uma afirmação predicativamente construída. É uma experiência do outro, empiricamente vivida e colocada, por Husserl (2002) [Apud por Bicudo], fenomenologicamente em epoché, de modo que se escavam sentimentos, emoções, intuições, reflexões que são vividos nessa experiência. Esse procedimento conduz regressivamente às operações constitutivas desse conhecimento, a partir do movimento de auto-focar-se e auto-perceber-se, efetuado por aquele que procede à redução mencionada, fundado na reflexão do que se mostra na vivência com o outro. No ato da percepção entropática se estabelece uma ligação permitida pela constatação do "igual a mim", ou seja, o outro a quem me posso expor, pois pode compreender comigo o que estou compreendendo de minha experiência vivida (BICUDO, 2016, p. 39-40, grifo nosso).

Em acordo com o exposto por Bicudo (2016), a intropatia é relacional (exige um vínculo com outro); é percebida intersubjetivamente; é experiencialmente vivenciada a partir da suspensão dos preconceitos (epoché); é respeitosa tanto dos outros, quanto de nós mesmos.

Essa atitude intropática tem que se manter por tempo suficiente para que seja possível a construção de uma descrição densa (GEERTZ, 2008; RUIZ; ISPIZÚA, 1989), isto é, detalhada, minuciosa, profunda e contendo todos os detalhes explícitos e os significados subjacentes, relativos à situação social em estudo.

Dessa forma, desde o ponto de vista cognitivo, o pesquisador qualitativo realiza uma tarefa intelectualmente exigente (González, 1998), intensa e complexa, que requer sua permanência prolongada no local do estudo, para observar, ouvir, perguntar, registrar e relacionar eventos, fatos, pistas etc. Tudo isso leva a: Interpretar (equivalente a dar significado a uma ação, levando em consideração as coordenadas contextuais em que foi realizada e o significado atribuído a ela por seus próprios atores); Compreender as ações sociais, que exigem que o pesquisador: (a) revele o objetivo que justifica sua execução em uma situação social específica; (b) perceba a meta o objetivo cuja conquista é perseguida por tal ação; (d) reconheça o propósito que incentiva o ator ao executá-la, e (e) desvende o significado oculto que ela tem para seus protagonistas.

Descrever, Interpretar e Compreender são três dos compromissos cognitivos fundamentais de um pesquisador qualitativo; eles, por sua vez, dão origem a três outros níveis de ação: (a) Ação Consciente e Explícita (participação concreta em acontecimentos e fatos sociais específicos); (b) Reflexão (elaboração de ideias, propostas, projetos, abordagens, modelos ou esquemas conceituais, teóricos, ideais, etc.); e, (c) Críticas 
(criação de espaços para a vigilância ativa das ações de atores da administração pública com quem se têm reservas ou desacordos).

Como esperado, o desenvolvimento da atividade intelectual do pesquisador vinculada aos compromissos cognitivos mencionados acima, requer contrastar e comparar observações relacionadas à mesma situação, oriundas de diferentes fontes, obtidas de diferentes formas, conceituadas à luz de teorias diversas, capturados em vários momentos, localizados em diferentes contextos, organizados em diferentes níveis e oferecidos com diferentes formatos de apresentação.

Essa multiplicidade de visões deve ser sintonizada, ajustada e focada de forma a contribuir para a criação de uma imagem que represente o mais fidedignamente e fielmente possível, toda a complexidade do assunto em estudo, viável através dos procedimentos de triangulação, conceituada como uma estratégia que permite articular "os diversos ângulos de análise, as diversas necessidades de recortes e ângulos para que a visão não seja limitada e o resultado não seja restrito a uma perspectiva" (TUZZO; BRAGAS, 2016, p. 141). Dada a importância da triangulação para garantir a robustez de pesquisa, a seguir são oferecidos mais detalhes em relação com essa noção.

\section{O Conceito de Triangulação}

A ideia da triangulação está entre os conceitos fundamentais com base nos quais é estabelecida a qualidade das informações coletadas nos estudos realizados a partir de alguma das várias perspectivas qualitativas de pesquisa; entre os princípios filosóficos que servem de alicerse aos procedimentos de triangulação, podem ser mencionados os seguintes: (a) existem realidades múltiplas; (b) o conhecimento avança em direção à divergência, e não à convergência; (c) na esfera social, tudo está inter-ligado com tudo; (d) cada pessoa constrói conhecimento com base nas coordenadas que definem seu respectivo lugar epistemológico.

O conceito de triangulação é uma extensão transdisciplinar, proveniente da Geodésia (ciência que lida com a forma e a dimensão da Terra), usada pelos agrimensores para localizar pontos em um terreno; também é usado por navegadores marítimos, estrategistas militares e astrônomos que costumam usar vários locais de referência para localizar pontos no espaço ou objetos específicos (BÁEZ, 1999, novembro, p. 2).

Assim, com a triangulação é pretendido localizar um ponto no espaço, usando pelo menos outros três pontos que sirvam de referência; de fato, qualquer ponto A no espaço 
é determinado por três coordenadas, isto é, $A=\left(A_{1}, A_{2}, A_{3}\right)$. Para saber onde é que o ponto A está localizado, é suficiente encontrar $\mathrm{A}_{1}, \mathrm{~A}_{2}$ e $\mathrm{A}_{3}$. Matematicamente, trata-se de criar três equações independentes que envolvam essas três incógnitas e com essas equações propor um sistema compatível determinado de equações que, quando resolvido, permite obter os valores de $\mathrm{A}_{1}, \mathrm{~A}_{2}$ e $\mathrm{A}_{3}$ que servem para localizar o ponto A.

Portanto, a triangulação, como um procedimento para localizar pontos relacionados a outros que servem como referência, constitui a ideia básica que é transferida para a pesquisa qualitativa; nesse caso, o "ponto" cujas "coordenadas posicionais" devem ser localizadas é constituído por uma expressão geral de caráter teórico (intuição, conjectura, conclusão, afirmação preliminar, categoria, hipótese anterior, etc.); então, trata-se de procurar entre a massa usual de informações característica da pesquisa qualitativa, os componentes dessas coordenadas posicionais, que são determinados com base em: as informações coletadas, as perspectivas dos observadores que participaram em sua coleta; as teorias que foram adotadas como base das interpretações; a estratégia (organização sistémica de métodos, recursos, instrumentos, técnicas, procedimentos) que foi desenvolvida para reunir as informações que são a base para a construção dos dados. A triangulação consiste, então, na comparação e contraste desses dados (DENZIN, 1978), por meio de procedimentos de controle cruzado (CARR; KEMMIS, 1983). Com isso, o que se busca é

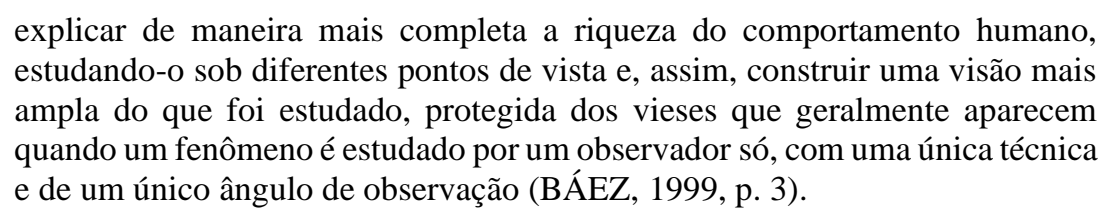

A Figura 2 ilustra a triangulação na observação de uma situação de ensino e aprendizagem.

Figura 2: Triangulação na observação de uma situação de ensino e aprendizagem

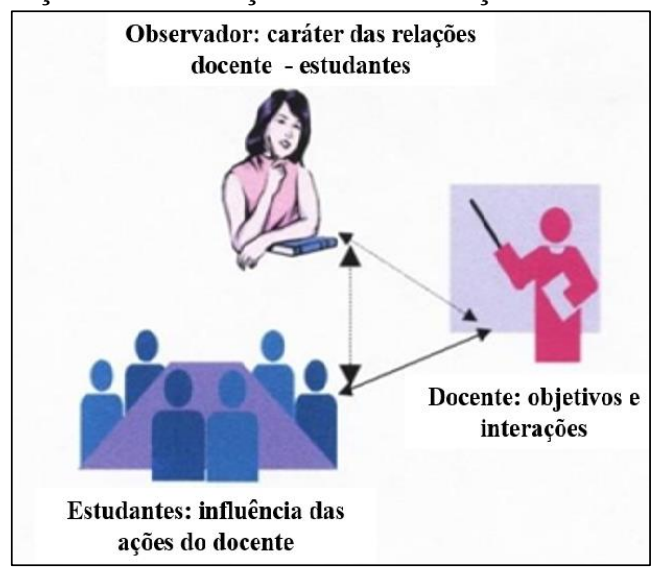

Fonte: Autoria Própria 
Na Figura 2, pretende-se representar o estudo de uma situação de ensino e aprendizagem na qual o professor, os alunos e um eventual observador ocupam posições relativamente vantajosas para oferecer, cada um deles, uma perspectiva específica dessa situação:

O professor está localizado em uma posição ideal para acessar as intenções e objetivos da situação de ensino, por meio da introspecção; os alunos ocupam um lugar privilegiado para explicar como as ações do professor influenciam sua própria maneira de responder à situação; finalmente, o observador está em uma posição excelente para coletar informações sobre as características da interação entre professor e alunos (BÁEZ, 1999, p. 4).

O objetivo é promover a convergência dessas três visões complementares sobre a mesma situação, que se fortalecem mutuamente.

A oportunidade de se localizar em diferentes posições, possibilita o surgimento de várias modalidades de triangulação; assim, por exemplo, no caso dos dados, é possível considerar sua persistência ao longo do tempo, coletando informações básicas em momentos diferentes; examinar sua coincidência quando a informação é coletada em diferentes partes; verificar sua fidedignidade usando pessoas ou grupos diferentes para obter informações sobre o mesmo problema. No caso dos pesquisadores, suas anotações escritas podem ser contrastadas para verificar se registraram o mesmo aspecto em relação a um tema comum; quanto às teorias, podem ser aplicados postulados conceituais opostos ou contraditórios entre si, com a finalidade de obter uma interpretação mais abrangente de algum fato ou ação.

Para obter mais informações sobre a triangulação na pesquisa qualitativa, consulte: MORSE (1991), COWMAN (1993), DENZIN (1978), KIMCHI, POLIVKA; STEVENSON (1991), BOGDAN; BIKLEN (1982).

Algumas das possíveis modalidades de triangulação são mostradas no Quadro 2.

\begin{tabular}{|c|c|}
\hline CRITÉRIOS & VARIANTES \\
\hline 1. Tempo & $\begin{array}{l}\text { 1.1 Dados do mesmo grupo em momentos diferentes } \\
\text { 1.2 Dados ao mesmo tempo de diferentes grupos }\end{array}$ \\
\hline 2. Espaço & 2.1 Estudo do mesmo fenômeno em diferentes áreas geográficas \\
\hline 3. Níveis Combinados & $\begin{array}{l}\text { 3.1 Estudo de um fenômeno a partir de perspectivas sequenciadas e / ou } \\
\text { hierarquizadas: individual, grupal ou organizacional }\end{array}$ \\
\hline 4. Teorias & $\begin{array}{l}\text { Jso de várias teorias para resolver uma situação, em vez de considerar } \\
\text { apenas um ponto de vista único. }\end{array}$ \\
\hline
\end{tabular}




\begin{tabular}{|l|l|}
\hline $\begin{array}{l}\text { 5. Pesquisadores, observadores } \\
\text { ou participantes }\end{array}$ & $\begin{array}{l}\text { Usar as informações complementares entre si, fornecidas por vários } \\
\text { observadores; Cada um contribui com seu próprio estilo de coleta e } \\
\text { processamento de informações. }\end{array}$ \\
\hline 6. Métodos & $\begin{array}{l}\text { 6.1 Vários métodos para o mesmo problema (entre) } \\
6.2 \text { O mesmo método em diferentes ocasiões (dentro) }\end{array}$ \\
\hline 7. Dados & $\begin{array}{l}7.1 \text { Obter dados em momentos diferentes } \\
7.2 \text { Obter dados em diferentes partes } \\
7.3 \text { Obter dados fornecidos por diferentes sujeitos }\end{array}$ \\
\end{tabular}

Fonte: Autoria Própria

\section{Entrevista: técnica privilegiada para obter informações em Pesquisa Qualitativa}

Como apontado por Bicudo (2016) “A intropatia é basicamente conhecimento do outro que se desenvolve nas vivências em que o outro é dado (trazido, exposto) ao eu em sua corporeidade. É uma percepção constituinte da intersubjetividade" (BICUDO, 2016, p. 39), para o pesquisador qualitativo é essencial se apropriar das experiências daqueles que, juntamente com o ele, co-protagonizam as situações sociais em estudo; para isso, devem ser promovidas experiências diretas que viabilizem a penetração no campo do outro e se fazer parte de seu próprio modo de vida; isso é possível através da entrevista em profundidade (MORÉ, 2015).

A entrevista constituiu uma situação social (CASTILLO, 1984), na qual são geradas interações verbais e não verbais, entre o entrevistador e o(s) entrevistado(s); isso fornece informações coletadas pelo entrevistador para, com base nelas e após de textualixadas, gerar uma narrativa verbal (em forma escrita) que carrega informações úteis para a pesquisa.

Para realizar uma entrevista, o pesquisador pode usar instrumentos que constituam mecanismos de percepção; isso incluiu uma Pauta de Entrevista, que pode ser fechada ou aberta; a primeira gera uma entrevista estruturada, enquanto a segunda leva para uma entrevista não estruturada, na qual é possível distinguir os seguintes tipos: (a) Focalizada (estuda as motivações das ações sociais); (b) Clínica (aborda sentimentos e atitudes dos atores sociais); (c) Não dirigida (analisa tanto sentimentos quanto emoções dos atores).

Com base na abordagem pentadimensional (González, 2005, 2008), pode-se afirmar que a dimensão ontológica da entrevista se expressa na situação social que protagonizam o entrevistador e o entrevistado. As interações entre estes dois protagonistas, têm caráter epistemológico, onde estão presentes um sujeito dual (entrevistado-entrevistador) que -por meio de uma relação dialógica- constrói um relato 
verbal que contém a informação que serve de base para a construção dos dados relativos ao assunto no estudo.

A dimensão metodológica é mostrada nos instrumentos, recursos e outros dispositivos utilizados ou aplicados durante a entrevista, como também assim nos momentos, oportunidades e condições estabelecidas para sua realização: como, quando, onde e com que? são algumas das perguntas cujas respostas contribuem para explicitar a dimensão metodológica da entrevista.

A dimensão axiológica e associada com as condições que são estabelecidas para realizar uma entrevista; os indicadores desta dimensão são: salvaguarda da integridade moral e ética do entrevistado; respeito a sua perspectiva; e confidencialidade no tratamento das informações fornecidas, entre outros.

Por fim, a dimensão teleológica e identificada no reconhecimento da finalidade atribuída à entrevista; esta pode ser usada para fins diversos como seriam os de: diagnóstico, orientação, terapia e/ou pesquisa.

Para ilustrar visualmente a concepção da entrevista defendida aqui e construída a partir da leitura do trabalho de TORREALBA (1999), na Figura 3, é mostrado um mapa conceitual (NOVAK, 1998) que resume e integra a abordagem pentadimensional, concebida como uma "ferramenta analítica para fornecer a interpretação cognitiva da atividade de pesquisa" (GONZÁLEZ, 2005; p. 11) 
Figura 3: Uma visão introdutória da entrevista gerada a partir da leitura de TORREALBA (1999)

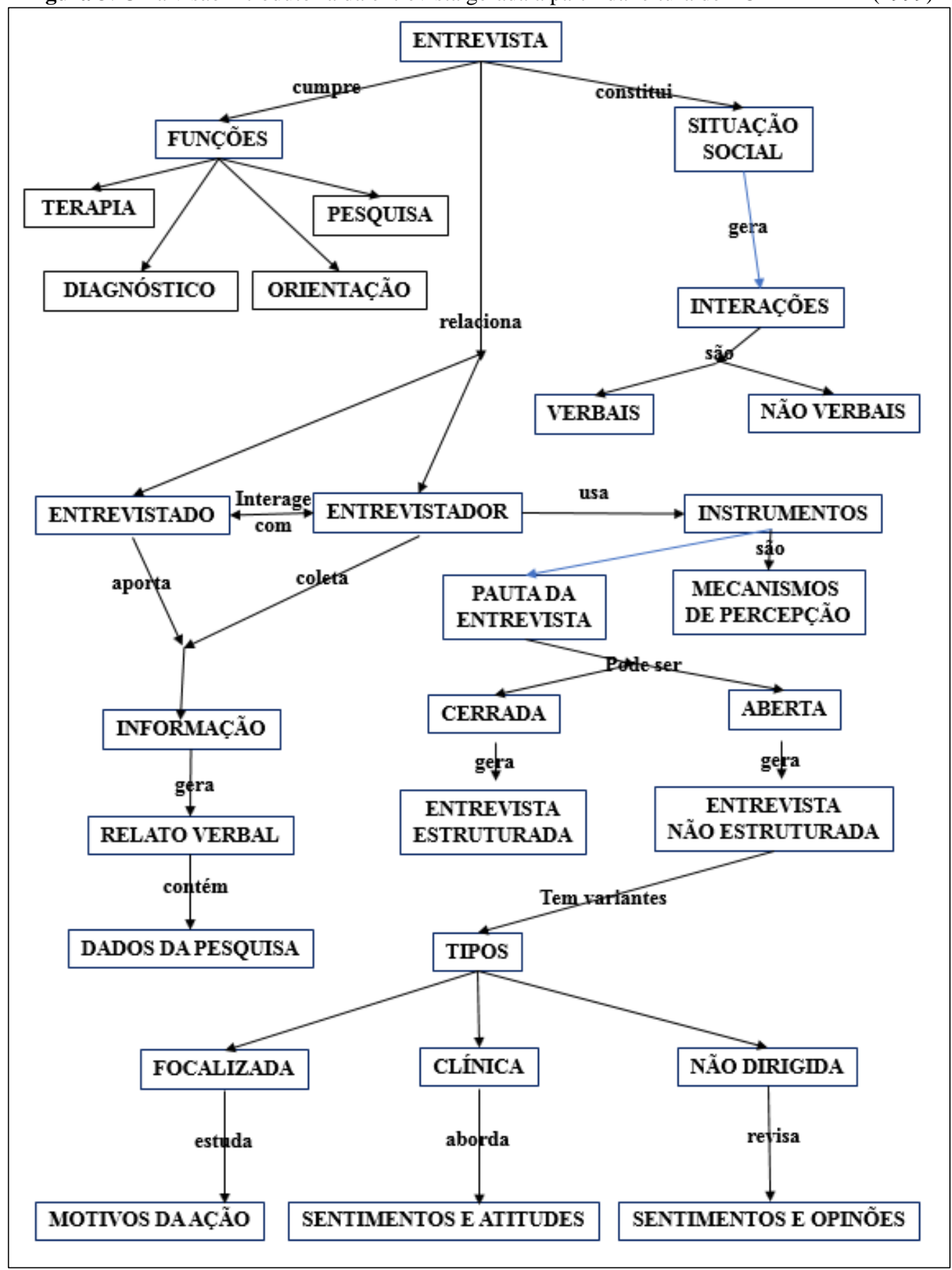

Fonte: Autoria Própria

\section{Reflexão Final}

Mesmo que a controvérsia entre as perspectivas quantitativa e qualitativa adoptadas no desenvolvimento de pesquisas sociais e educacionais e, em geral, nos diferentes campos das ciências humanas, foi iniciada há muito tempo, as brigas entre pesquisadores quantitativistas e qualitativistas vez por outra é atualizada. Neste ensaio 
algumas ideias sobre vários dos principais conceitos da pesquisa qualitativa foram colocadas na discussão.

A primeira questão que foi colocada é que não é adequado falar de pesquisa qualitativa como se fosse uma forma única de fazer pesquisa. Pelo contrário é imprescindível assumir e clarificar a polissemia dessa expressão, derivada de vários fatores como, por exemplo, seus baseamentos filosóficos, e reconhecer as variações que se dão entre elas.

Um outro assunto discutido foi que as diferenças entre as opções quantitativa e qualitativa de fazer pesquisa não são só de caráter metodológico, senão que incluem ao menos quatro outras dimensões (epistemológica, ontológica, axiológica e teleológica).

A noção chave que atravessa o texto é a da subjetividade do pesquisador qualitativista. Por isso, abriu-se espaço para refletir sobre o caráter dele como o principal dispositivo da sua própria pesquisa.

Por fim, é esperado que os leitores façam suas apreciações porque... a reflexão deve continuar.

O Papel do pesquisador na pesquisa qualitativa constitui a segunda parte deste artigo.

Em relação ao pesquisador qualitativo, é apresentada a noção de Lugar

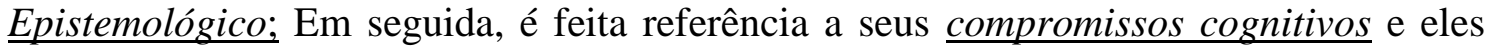
estão relacionados a três das cinco dimensões que González $(2005,2008)$ propõe para analisar a pesquisa socioeducativa, a saber: teleológica, ontológica e epistemológica (as outras duas dimensões são metodológica e axiológica).

Após o exposto, é discutido o conceito de triangulação (COWMAN, 1993; DENZIN, 1978), uma questão metodológica crucial na pesquisa qualitativa, uma vez que sua implementação está vinculada à qualidade e robustez das informações que servem de base para a construção das expressões teóricas gerais que compõem o discurso de uma pesquisa predominantemente qualitativa.

O artigo culmina com a apresentação de uma visão introdutória da entrevista, uma técnica que desempenha um papel importante na pesquisa qualitativa, pois é uma das maneiras pelas quais a ideia de intersubjetividade é materializada. Por fim, é incluído um mapa conceitual que ilustra as inter-relações entre os diferentes aspectos que o autor destaca na entrevista como uma técnica privilegiada para obter as informações que são necessárias numa pesquisa de natureza qualitativa. 


\section{Referências}

ALVARADO, C. G. Debilidades de los Modelos Cualitativos y Cuantitativos. 2003. Ensaio de Avaliação Final, apresentado como requisito parcial para a aprovação da disciplina "Métodos Qualitativos de Pesquisa Educacional - Programa de Doutorado em Educação, Instituto Pedagógico "R. A. Escobar Lara", Universidade Pedagógica Experimental Libertador, Maracay, Aragua, Venezuela, 2003.

ARIAS VALENCIA, M. M. La triangulación metodológica: sus principios, alcances y limitaciones. Investigación y Educación en Enfermería, Medellín, v. XVIII, n. 1, p. 13-26, mar. 2000, pp. 13-26. Disponível em:

https://www.uv.mx/mie/files/2012/10/triangulacionmetodologica.pdf. Acesso em: 01 mar. 2020.

ATKINSON, P.; DELAMONT, S.; HAMMERSLEY, M. (1988). Qualitative Research Traditions: A British Response to Jacob. Review of Educational Research, Washington, v. 58, n. 2, p. 231-250. https://doi.org/10.2307/1170335.

\section{BÁEZ, E. Problemas Filosóficos y Epistemológicos Subyacentes en el Uso de los} Procedimientos de Triangulación en la Investigación Cualitativa. 1999. Ensaio de Avaliação Final, apresentado como requisito parcial para a aprovação da disciplina "Métodos Qualitativos de Pesquisa Educacional" - Programa de Doutorado em Educação, Instituto Pedagógico "R. A. Escobar Lara", Universidade Pedagógica Experimental Libertador, Maracay, Aragua, Venezuela, 1999.

BICUDO, M. A. V.; COSTA, A. P. Leituras em pesquisa qualitativa. São Paulo: Editora Livraria da Física. 2019.

BICUDO, M. A. V. Sobre história e historicidade em Edmund Husserl. Cadernos da EMARF, Fenomenologia e Direito, Rio de Janeiro, v.9, n.1, p.1-174, abr./set.2016. Disponível em: http://www.mariabicudo.com.br/resources/ARTIGOS/Sobre historia historicidade em Edmund Husserl.pdf. Acesso em: 31 ago. 2020.

BICUDO, M. A. V.; KLÜBER, T. E. A questão de pesquisa sob a perspectiva da atitude fenomenológica de investigação. Conjectura: filosofia e educação, Caxias do Sul, v. 18, n. 3, p. 24-40, 2013.

BISOL, C. A. Estratégias de pesquisa em contextos de diversidade cultural: entrevistas de listagem livre, entrevistas com informantes-chave e grupos focais. Estud. psicol., Campinas, v. 29, supl. 1, p. 719-726, dec. 2012. Disponível em: http://www.scielo.br/scielo.php?script=sci_arttext\&pid=S0103166X2012000500008\&lng=en\&nrm=iso. Acesso em: 01 mar. 2020.

BOGDAN, R. C.; BIKLEN, S. K. Qualitative research for education: An introduction to theory and methods. Boston: Allyn and Bacon, 1982.

BOSI, M. L. M. Desafios atuais para a pesquisa qualitativa: Considerações no cenário da saúde coletiva brasileira. Forum Sociológico, [S.I], v. 24, 2014.

BOSI, M. L. M. Pesquisa qualitativa em saúde coletiva: panorama e desafios. Ciênc. saúde coletiva, Rio de Janeiro, v. 17, n. 3, p. 575-586, mar. 2012. Disponível em: http://www.scielo.br/pdf/csc/v17n3/v17n3a02.pdf. Acesso em: 02 mar. 2020.

CAPRA, F. La Trama de la Vida: una nueva perspectiva de los sistemas vivos. Barcelona (España): Editorial Anagrama. 1998. 
CAPRA, F.; STEINDL-RAST, D. Pertencendo ao universo: explorações nas fronteiras da ciência e da espiritualidade. São Paulo: Editora Cultrix Ltda, 1998.

CARR, W.; KEMMIS, S. Becoming critical: knowing through action research. Geelong, Vic. Aust. Deakin University Press, 1983.

CASTILLO, V. de. (1984). Situaciones Sociales y Observación Participante. Paradigma, Maracay, v.1- 3, p. 7-19. Disponível em: http://revistaparadigma.online/ojs/index.php/paradigma/article/view/75.

CÓRDOVA, V. Hacia una Sociología de lo Vivido. Comisión de Estudios de Postgrado, Facultad de Ciencias Económicas y Sociales, Universidad Central de Venezuela. CaracasVenezuela: Tropykos, 1995.

COWMAN, S. Triangulation: a means of reconciliation in nursing research. Journal of Acvanced Nursing, [S.I], v.18, p. 788-792, 1993. https://doi.org/10.1046/j.13652648.1993.18050788.x

DENZIN, N. K. Strategies of Multiple Triangulation. In: The Research Act: A theoretical Introduction to Sociological Methods. Part IV. Strategies of Triangulation and the Art of Doing Sociology. New York: McGraw-Hill Book Company, 1978. p. 291 - 307.

DENZIN, Norman K; LINCOLN, Yvonna. S. (ed.). Handbook of Qualitative Research. Thousand Oaks, CA: Sage. 1994.

EISNER, E. W. The enlightened eye: Qualitative inquiry and the enhancement of educational practice. New York, NY: Macmillan Publishing Company, 1991.

ENRIQUEZ, P. G.; VILLAZÓN, A. Investigación Acción y Práctica Docente: Una relación en construcción. IDEA. Revista de la Facultad de Ciencias Humanas, San Luis, Argentina, n. 19. p. 75-98, 1995.

FALS BORDA, O. Una Sociologia Sentipensate para América Latina. Antologia de textos selecionados e presentados por Víctor Manuel Moncayo. Bogotá: CLACSO/Siglo del Hombre Editores, 2009.

FERRAROTTI, F. História e histórias de via. O método biográfico nas Ciências Sociais. Tradução de Carlos Eduardo Galvâo Braga e Maria da Conceição Passeggi. Natal, RN: EDUFRN, 2014.

GARCÍA, C. El Explicar y el Comprender en la investigación científica: una perspectiva epistemológica. 2000. Ensaio de Avaliação Final, apresentado como requisito parcial para a aprovação da disciplina "Métodos Qualitativos de Pesquisa Educacional" - Programa de Doutorado em Educação, Instituto Pedagógico "R. A. Escobar Lara”, Universidade Pedagógica Experimental Libertador, Maracay, Aragua, Venezuela, 2000.

GEERTZ, C. Uma descrição densa: por uma teoria interpretativa da cultura. In: GEERTZ, Clifford. A Interpretação das Culturas. 1ed., 13 reimpr., Rio de Janeiro: LTC, 2008. p.3-21.

GLASER, B. G.; STRAUSS, A. L. The discovery of grounded theory. Chicago, IL: Aldine Publishing Company. 1967.

GOETZ, J. P.; LECOMPTE, M. D. Etnografía y Diseño cualitativo en Investigación Educativa. Madrid: Ediciones Morata, 1988. 
GONZÁLEZ, F. E. Uso del enfoque pentadimensional en el análisis interno de productos escritos de investigación. Revista Educação em Questão, [S.I], v. 23, n. 9, p. 7-15, 15 ago. 2005.

GONZÁLEZ, F. Investigación cualitativa: La discusión debe continuar. Vagazine On-line [Revista en Línea]. Disponible: http://members.tripod.com/ vagazine/fred1.html. Consulta em: feb 1999.

GONZÁLEZ, F. E. La Investigación Cualitativa: Una discusión necesaria. In: GONZÁLEZ, F. Textos de Investigación cualitativa: Una Selección Intencionada. Dossier Didático de Lecturas utilizado en el desarrollo del Seminario Metodos Cualitativos de Investigacion Educacional en el programa del Primer Doctorado No Escolarizado nn Educación Superior, Centro de Etudios de Postgrado y de Investigación en Educación Superior (CEPIES), Convenio Universidad de Bremen (Alemania) - Universidad Mayor de San Andrés, La Paz, Bolivia, 2006.

GONZÁLEZ, F. E. Apuntes para una crítica pentadimensional de la investigación socioeducativa. Revista Educação em Questão, [S.I.], v. 32, n. 18, ago. 2008.

GONZÁLEZ, F. E. Metacognición y aprendizaje estratégico. Rev. de Inv. Educ., [S.I.], v. 2, n. 2, p. 127-136, 2009.

GONZÁLEZ, F. Acerca de la Metacognición. Revista Paradigma, Maracay, Revista Educação em Questão v. 14-17, n. (1y2), p.109-135, jun. 1996.

GONZÁLEZ, F. Metacognición y Tareas Intelectualmente Exigentes: El caso de la Resolución de Problemas Matemáticos. Zetetiké, Campinas, v. 6, n. 9, p. 59-87, 1997.

HABERMAS, J. The theory of communicative action. Reason and the rationalizalion of society. Boston: Beacon Press, 1984.

HABERMAS, J. The theory of communicative action. Lifeworld and sistem: A critique of functionalist reason. Boston: Beacon Press, 1987.

HIDALGO, B.; GONZALEZ, F. E. Metabolización de información: un modelo dinámico para interpretar el proceso de producción de conocimiento. Investigación y Postgrado, Caracas, v. 24, n. 1, p. 10-45, ene. 2009. Disponible en:

http://ve.scielo.org/scielo.php?script=sci_arttext\&pid=S1316-

00872009000100002\&lng=es\&nrm=iso. Accedido en: 31 ago. 2020.

JACOB, E. (1987). Qualitative Research Traditions: A Review. Review of Educational Research, [S.I.], v. 57, n. 1, p. 1-50, 1987.

JORDAN, D. Contemporary Methodological Approaches to Qualitative Research: A Review of The Oxford Handbook of Qualitative Methods. The Qualitative Report, [S.I.], v. 23, n. 3, p. 547-556, 2018.

KEMMIS, S.; MacTAGGART, R. Cómo Planificar la Investigación Acción. Barcelona (España): LAERTES, S. A. de Ediciones, 1992.

KIMCHI, J.; POLIVKA, B.; STEVENSON, J. S. Triangulation: Operational Definitions. Metodology Corner. Rev. Nursing Research, [S.I.], v.40, n. 6, p 364-366, 1991.

LINCOLN, Y. S.; GUBA, E. G. Naturalistic inquiry. Beverly Hills, CA: Sage Publications, Inc, 1985. 
MARTÍNEZ, M. El comportamiento Humano: Nuevos Métodos de Investigación. México, D. F.: Editorial Trillas. 1989.

MARTÍNEZ, M. La Investigación Cualitativa Etnográfica en Educación: Manual Teórico Práctico. Caracas: Litexsa Venezolana, S. A. 1991.

MARTÍNEZ, M. La Investigación Cualitativa Etnográfica. México, D. F.: Trillas. 2000.

MARTINO, L. M. S.; LOPES, A. G.; SOUZA, V. R. P. A entrevista na pesquisa em comunicação: reflexões metodológicas sobre duas experiências práticas. Revista Sociais e Humanas, [S.1.], v. 32, n. 3, fev. 2019. Disponível em:

https://periodicos.ufsm.br/sociaisehumanas/article/view/38788 . Acesso em: 01 mar. 2020.

MARTINS, J.; BICUDO, M. A. V. A Pesquisa Qualitativa em Psicologia Fundamentos e Recursos Básicos. 2. ed. São Paulo: Moraes, 1994.

MELLA, O. Naturaleza y Orientaciones Teórico-Metodológicas de la Investigación Cualitativa. Documento en Línea, 1998. Disponible en:

https://marcoquiroz.files.wordpress.com/2018/08/mella.pdf . Consulta: 22 mar. 2020.

MONTAGNER, M. Biografia coletiva, engajamento e memória: a miséria do mundo. Tempo Social, [S.I.], v. 21, n. 2, p. 259-282, jan. 2009. Disponível em: http://www.revistas.usp.br/ts/article/view/12601. Acesso em: 27 mar. 2020.

MONTERO-SIEBURTH, M. Corrientes, Enfoques e Influencias de la Investigación Cualitativa para Latinoamérica. La Educación (Revista Interamericana de Desarrollo Educativo), [S.I.], v. XXXVII, n. 116, p. 491-517, 1993.

MORÉ, C. L. O. O. A “entrevista em profundidade" ou "semiestruturada", no contexto da saúde Dilemas epistemológicos e desafios de sua construção e aplicação. In: CONGRESSO IBEROAMERICANO DE INVESTIGAÇÃO QUALITATIVA, Aracaju. Atas do CIAIQ 2015, v. 3: Atas - Investigação Qualitativa nas Ciências Sociais, Aracaju, 2015. p.126-131. Disponível em: https://proceedings.ciaiq.org/index.php/ciaiq2015/article/view/158/154.

MORENO, A., et al. Y salimos a matar gente. Investigación sobre el delincuente venezolano violento de origen popular. I y II, Plasarte, C. A., Caracas, 2009.

MORERA, M. El concepto de variante en lingüística. Estudios de Lingüística del Español, [S.I.], v. 39, p. 11-29, 2018.

MORSE, J. M. Approaches to Qualitative-Quantitative Metodological Triangulation. Metodology Corner. Rev. Nursing Research, [S.I.], v. 40, n. 1, 1991.

MURCIA, N.; JARAMILLO, L. G. La complementariedad como posibilidad en la estructuración de diseños de investigación científica. Cinta de Moebio, [S.I.], v. 12, p.194-204. 2001.

MYERS, M. D. "Qualitative Research in Information Systems". MIS Quarterly, [S.I.], v. 21, n. 2, p. 241-242, jun. 1997. Association for Information Systems (AISWorld) Section on Qualitative Research in Information Systems, updated version, last modified: January 15, 2020 Disponivel em: www.qual.auckland.ac.nz Acesso em: 20 mar. 2020.

NOVAK, J.D. (1998). Conocimiento e Aprendizaje: Los mapas conceptuales como herramientas facilitadoras para escuelas y empresas. Madrid: Editorial Alianza. 
OSTROM, E. A general framework for analyzing sustainability of social ecological systems. Science, [S.I.], v. 325, p. 419-422, 2009.

PATTON, M. Q. Qualitative Evaluation and Research Methods. 2. ed. Newbury Park, CA: Sage Publications, Inc. 1990.

PERUZZO, C. M. K. Pressupostos epistemológicos e metodológicos da pesquisa participativa: da observação participante à pesquisa-ação. Estudios sobre las Culturas Contemporáneas, [S.I.], v. XXIII, supl. 3, 2017.

PEZZATO, L. M.; BOTAZZO, C.; L'ABBATE, S. O diário como dispositivo em pesquisa multicêntrica. Saude soc., São Paulo, v. 28, n. 3, p. 296-308, sep. 2019 Available from: http://www.scielo.br/scielo.php?script=sci_arttext\&pid=S0104-12902019000300296. Acess on: 27 mar. 2020.

PUJADA, M. J. J. El Método Biográfico: El uso de las historias de vida en ciencias sociales. Tarragona (España): Centro de Investigaciones Sociológicas: (Série Cuadernos Metodológicos, 5), 2002.

RENOSTO, A.; TRINDADE, J. L. de A. A utilização de informantes-chave da comunidade na identificação de pessoas portadoras de alterações cinético-funcionais da cidade de Caxias do Sul, RS. Ciênc. saúde coletiva, Rio de Janeiro, v. 12, n. 3, p. 709-716, june 2007. Available from: http://www.scielo.br/scielo.php?script=sci_arttext\&pid=S1413-

81232007000300021\&lng=en\&nrm=iso. Access on: 01 mar. 2020.

RODRÍGUEZ REVOREDO, M. A. Metodología Cuantitativa vs. Cualitativa: Una Polémica en Extinción. 2. ed. Xalapa Veracruz México: Instituto de Estudios de la Tercera Cultura S.C, 2015.

RUIZ OLABUÉNAGA, J. I.; ISPIZUA URIBARRI, M. A. La Descodificación de la Vida Cotidiana. Bilbao: Universidad de Deusto, 1989.

RUSQUE, A. M. De la Diversidad a la Unidad en la Investigación Cualitativa. Valencia (Venezuela): Vadell Hermanos Editores, C. A., 2001.

SALAS SOLÍS, M. E. La Explicación em las Ciencias Sociales: Consideraciones Intempestivas contra el Dualismo Metodológico em la Teoría Social. Reflexiones, Costa Rica, v. 84, n. 2, p. 51-60, 2005. Disponível em: https://revistas.ucr.ac.cr/index.php/reflexiones/article/view/11421 Acesso em: 21 mar. 2020.

SANDIA, L. Domingo y Carmen: Dos Subjetividades de Carne y Hueso. 1999. Ensaio de Avaliação Final, apresentado como requisito parcial para a aprovação da disciplina "Métodos Qualitativos de Pesquisa Educacional" - Programa de Doutorado em Educação, Instituto Pedagógico "R. A. Escobar Lara", Universidade Pedagógica Experimental Libertador, Maracay, Aragua, Venezuela, 1999.

SANTOS, G. T. dos. et al. Método para Aplicar Entrevistas em Profundidade: Avaliando Causas de Baixo Desempenho em um Operador Logístico. Revista Gestão Industrial. [S.I.], v. 12, n. 4, p. 103-126, 2016.

SANTOS, J. L. G. et al. Análise de dados: comparação entre as diferentes perspectivas metodológicas da Teoria Fundamentada nos Dados. Revista da Escola de Enfermagem da USP, [S.I.], v. 52 de 2018, elocation e03303. 
STRAUSS, A.; CORBIN, J. Pesquisa qualitativa: técnicas e procedimentos para o desenvolvimento de teoria fundamentada. 2. ed. Porto Alegre: Artmed, 2008.

STRAUSS, A.; CORBIN, J. Basics of qualitative research: Grounded theory procedures and techniques. Newbury Park, CA: Sage Publications, 1990.

TAQUETTE, S. R.; MINAYO, M. C. Análise de estudos qualitativos conduzidos por médicos publicados em periódicos científicos brasileiros entre 2004 e 2013. Physis, Rio de Janeiro, v. 26, n. 2, p. 417-434, jun. 2016. Disponível em:

http://www.scielo.br/scielo.php?script=sci arttext\&pid=S010373312016000200417\&lng=en\&nrm=iso. Acesso em: 02 mar. 2020.

TORREALBA, M. (1999). Entrevista en profundidad: Proceso de Categorización y Análisis de Datos. 1999. Ensaio de Avaliação Final, apresentado como requisito parcial para a aprovação da disciplina "Métodos Qualitativos de Pesquisa Educacional" - Programa de Doutorado em Educação, Instituto Pedagógico "R. A. Escobar Lara”, Universidade Pedagógica Experimental Libertador, Maracay, Aragua, Venezuela, 1999.

TORRRES, M. Variantes e Invariantes en los métodos empleados en la investigación cualitativa. 1999. Ensaio de Avaliação Final, apresentado como requisito parcial para a aprovação da disciplina "Métodos Qualitativos de Pesquisa Educacional" - Programa de Doutorado em Educação, Instituto Pedagógico "R. A. Escobar Lara", Universidade Pedagógica Experimental Libertador, Maracay, Aragua, Venezuela, 1999.

TUZZO, S. A.; BRAGA, C. F. O Processo de Triangulação da Pesquisa Qualitativa: O Metafenômeno como Gênese. Revista Pesquisa Qualitativa, São Paulo, v. 4, n.5, p. 140-158, ago. 2016. Disponível em: https://editora.sepq.org.br/rpq/article/view/38/31 Acesso: 31 ago. 2020.

VILLEGAS, M. M.; GONZALEZ, F. E. La construcción del conocimiento por parte de estudiantes de educación superior: Un caso de futuros docentes. Perfiles Educativos, México, v. 27 , n. 109-110, p. 117-139, ene. 2005. Disponible en:

https://www.redalyc.org/articulo.oa?id=13211006 Accedido en: 21 mar. 2020.

Recebido em: 28 de março de 2020.

Aceito em: 11 de agosto de 2020. 